\title{
Making customer integration in company processes persistent: Comparison of literature and industrial perspective
}

\author{
Simone Vogel ${ }^{1}$, Matthias Kreimeyer ${ }^{2}$, Ronny Richter ${ }^{2}$, Stefan Spinler ${ }^{1}$ \\ ${ }^{1}$ WHU - Otto Beisheim School of Management \\ simone.vogel@whu.edu \\ stefan.spinler@whu.edu \\ ${ }^{2}$ MAN Truck \& Bus SE \\ matthias.kreimeyer@man.eu \\ ronny.richter.a@man.eu
}

\begin{abstract}
Even though the topic of customer integration receives a lot of attention in the literature, especially due to the emergence of new Design Thinking methods, it continues to be a challenge in practice. Companies lack efficient mechanisms for the systematic and continuous integration of customers in order to generate benefits and to avoid further complicating their internal processes. In this paper, the as-is situation is examined to find out why the industrial applicability is so problematic. For this purpose, we conducted a literature review and collected empirical evidence within the focal company, a commercial vehicle manufacturer. We were thus able to determine decisive influencing factors that inhibit the practical implementation of customer integration and are not yet well enough understood in the literature.

The most important influencing factors all relate to the process on the organizational level. Customer integration requires a recurring process, which needs to be anchored in the organizational processes. In addition, a modular design is required that uses a common denominator to control the different views on the customer and the requirements of the various divisions and development phases. This kind of process dos not yet exist in literature. There are only a few limited models that combine several methods and go beyond the early development phase. These initial findings clearly indicate that practitioners lack a comprehensive approach that provides structure and persistence to the topic of customer integration in organizations.
\end{abstract}

\section{Keywords: Customer integration process, knowledge representation, persistence}

\section{Introduction}

In today's rapidly changing world, affected by emerging trends and challenges, it is vital to adapt flexibly to new requirements. Manufacturers must place the customer in focus to react quickly to rapidly changing needs and the demand for higher product differentiation (Kuhl \& Krause, 2019). Constantly evolving technologies mean that well-informed customers are more aware of their needs, giving them a precise conception of their ideal solution (Lorenzo-Romero 
et al., 2014). Business-to-business (B2B) customers with investment goods tend to have an even greater interest in customized solutions because they require tools with which they earn money (Jacob, 2006). This is the case, for example, with commercial vehicle (CV) original equipment manufacturers (OEM) who face extremely heterogeneous customers despite handling relatively small quantities (Kreimeyer et al., 2013). The heterogeneity results in countless configurations, which theoretically implies there is a customer for every configuration. Due to intense competition, CV OEMs face the conflict between reducing costs, optimizing the portfolios and the pressure to innovate, which may be resolved by a strong customer focus (Lindemann \& Baumberger, 2006; Pelka, 2018). This increasing focus on customer solutions demands the joint marketing of products and services, resulting in manufacturers transforming increasingly into providers of product-service systems (PSS) (Rexfelt et al., 2011). As in the case of the CV industry, e.g. telematics services installed in trucks require specific customer know-how.

Although understanding the customer is more important than ever before and customization is particularly suitable for the CV market, it remains a challenging task. The complex modular kits and technical production systems cannot be adapted flexibly, and there are long product life cycles of 15 years (Kreimeyer et al., 2013). With many locations and a centralized modular system at the same time, it is harder to make customer requirements tangible throughout the organization and to translate between different development phases and divisions, such as from sales to engineering. This gives rise to the overarching research question of how a customer integration model can be designed to transfer customer knowledge across divisions and along the entire product life cycle into a knowledge representation in the organization and ensure its persistence? To accomplish this, this paper first examines three sub-research questions:

1) Is the as-is situation regarding CI in practice satisfactory, and what is the problem?

2) What are the decisive influencing factors?

3) Based on these answers, how should a prospective CI model be designed?

\subsection{Context and gaps}

CI itself is not a novel topic, it has become standard in many industries and there is also an extensive literature. Especially in association with Design Thinking, there are many recent publications (Fuchs \& Golenhofen, 2019). There is a vast amount of literature on the objectives and methods of CI. Also, CI concerning new product development (NPD) with the aim of innovation during the early phase of development are well explored (Rexfelt et al., 2011). However, there are no comprehensive models that aim to address complexity in order to make it more applicable in practice. The few already known approaches concentrate on very limited areas, such as the early phase of product development. CI has more often been studied in the business-to-customer (B2C) sector than in B2B settings, even though this is more beneficial as there is trust and long-term relationships are formed between organizations (Jouny-Rivier et al., 2017). This applies in particular to the CV development, as these investment goods in the B2B sector have development cycles that extend over multiple years. Additionally, this industry is particularly suitable for CI due to the varying degree of customization resulting from extremely heterogeneous customer requirements, but this is hardly investigated. Given the importance of the transport industry to our entire economy and lives, it is surprising that OEMs have not addressed CI much earlier. The customers, e.g. freight forwarders, face diverse challenges at rather low margins and therefore, they need to have tools that do their job and make their business easier.

The novelty of this study consists in establishing persistence through a common denominator that encompasses all development phases, various divisions and different customer requirements. This makes the topic of CI more practicable, because it approaches the complexity and combines all partial aspects of CI into a comprehensive reusable model. The 
objective is to create a process that transfers the generated customer knowledge in a representative form and makes it persistent throughout the entire organization. The absence of such a holistic approach was only recently highlighted by Wuttke et al. (2019). Therefore, this paper explores why CI is not applied systematically and identifies the obstacles in practice. First, the influencing factors (IF) are examined based on the as-is situation to understand the problem in detail and as preparation for a further study on the aforementioned CI model. This is done through empirical evidence collected from interviews with experts and the research partner as well as a literature review. This problem-centred research project has a high practical relevance due to the close cooperation with a worldwide leading CV manufacturer. The research refers to the example of the $\mathrm{CV}$ development, but results are transferable to similar industries.

\subsection{Structure of this paper}

This paper is structured in four main parts. After an introduction in Section 1, the research design is explained in Section 2. Section 3 includes the findings of the literature review and the industrial perspective, which are compared. Lastly, Section 4 presents the discussion of these results and an initial CI model, the goal of this research clarification. Some implications for the further procedure of this research project arise from this.

\section{Research approach}

Overall, this research project is building on a multidisciplinary approach of Action Research (Lewin, 1951) through close collaboration between the scientists and the cooperation partner. A problem-centred approach is pursued to base the theory on meaningful organizational problems in order to jointly diagnose the problem and develop a solution (Bryman \& Bell, 2011). This paper corresponds to stage I, the research clarification, of the Design Research Methodology (DRM) framework (Blessing \& Chakrabarti, 2009), which provides a solid foundation for conducting exploratory-interpretive research. Stage I aims at understanding the problem and presenting a desired outcome. To achieve this and to compare the academic and practical perspectives, two main research strategies were combined, namely a literature review and a series of expert interviews. The use of multiple research methods contributes to the representativeness and validity of the results.

\subsection{Research design}

The first methodological approach applied is a literature review, similar to that of Zogaj \& Bretschneider (2012) and is not described in detail here. Since CI is a broad topic, the literature review mostly refers to the more recent publications and does not claim to represent a complete review. It was merely used to present the status quo of research and to compile known IF in order to gain a better understanding of the gap between academia and practice. Data for the review was collected through a computer search based on various electronic sources (EBSCO, JSTOR, ProQUest, Science Direct, Scopus, SpringerLink and the university's electronic book library). Due to CI's diversity, various synonyms were used as search terms, as in Fueller et al. (2014). The literature examined is from 2004 to 2020, with a focus on articles, books, conference papers and dissertations, and the results are discussed in the next section.

Secondly, qualitative in-depth interviews with experts from practice were conducted to gain a comprehensive problem understanding about the industrial applicability of CI, in the following titled as an industrial perspective. As Herfeld (2007) explains, the complexity of the problem requires looking at it through the eyes of the user if the academic solution is to lead to improvements in industrial processes. In order to increase validity, semi-structured questions were chosen to direct the discussions and ensure that research-relevant results are captured. 
There were seven abstract guiding questions (Q), but experts had the opportunity to provide more details at each point. Q1 asks for their professional experience to ensure in-depth industry knowledge to maximize the reliability of the results. This was reached as the experts have an average of 17 years of industry experience. Q2 is about the reasons for CI and serves to ensure that everyone has the same understanding, but also to point out the multifaceted goals. Q3-5 examine the as-is situation, whether CI takes place, if so how, and whether this is satisfactory. Finally, the desired situation for CI was questioned in Q7.

Test runs were carried out with the research partner to ensure that the questions were clear and not ambiguous. Interviews were recorded, transcribed and made anonymous. The format of the interviews varied between telephone calls and personal conversations, and the average duration was 40 minutes. A diverse set of stakeholders was used, including CV customers, experts representing various divisions from $\mathrm{CV}$ OEMs and also from OEMs of $\mathrm{CV}$-like products. The latter, e.g. tractor, tipper or bodybuilder, were included to ensure the generalizability. CV-like in this context stands for B2B sector, investment goods, long product lifecycles, relatively small quantities and variant-oriented product portfolios, which indicate heterogeneous customer requirements and the resulting need for CI. In total, 33 experts (cf. Table 1) from European corporations were interviewed. The results of these surveys are discussed in Section 3.2.

Table 1. Position and years of professional experience of experts

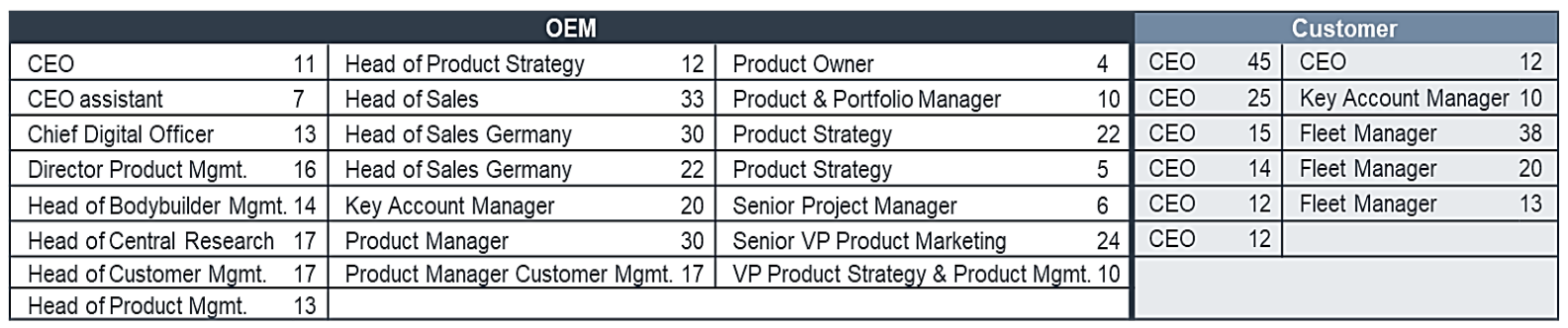

\section{Findings and observations}

This section provides a brief overview of CI in general and identifies the research gap. IF of CI found in literature are discussed in Section 3.2.2 and are thus not explicitly listed here.

\subsection{Literature review}

Nowadays knowledge sharing has become indispensable for creating innovations and challenging existing products, services and also processes and this demands collaboration with customers (Balau et al., 2020; Legardeur et al., 2010). Over time, various terminologies for CI have evolved, such as 'consumer involvement' or 'client integration' or 'customer partnership' (Fueller et al., 2014; Schweitzer et al., 2019), in this paper the term CI is used. Moeller (2008, p.202) distinguishes between the terms CI, customer participation, co-production and cocreation and, based on this, she defines CI "as combining customer resources (persons, possessions, nominal goods, and/or personal data) with the company resources, in order to transform customer resources". This corresponds to Jacob's (2006) view that CI is about combining the company's internal resources with the external ones, which customers bring as inputs input into organizational processes. Lorenzo-Romero et al. (2014) provide a compilation of the general theoretical background of CI with focus on customers' motivators to participate in co-creation. Especially in studies that examine both perspectives, the importance of the tradeoff between complexity and the expected benefit for the customer and the company becomes apparent (Jouny-Rivier et al., 2017; Kuhl \& Krause, 2019; Schweitzer et al., 2019).

The goals behind CI, e.g. improvement of existing solutions, innovation or creation of tailormade solutions, are also intensively researched because especially when several parties 
collaborate, clear communication about the benefits and sacrifices is crucial (Jouny-Rivier et al., 2017; Rexfelt et al., 2011). Pelka (2018) and Schweitzer et al. (2019) note that there is an extensive literature on CI with the goal of NPD and the focus on innovations, which counts among the main objectives of CI. Consequently, CI is crucial for the ideation phase, which occurs in the early stage of development (Ehlen, 2015; Enkel et al., 2005). Therefore, literature about CI often focuses on the early phase (Ernst et al., 2017; Pelka, 2018; Piller \& Vossen, 2010; Witell et al., 2011). Recent publications emphasize the importance of all phases and that CI hence changes (Kuhl \& Krause, 2019; Schweitzer et al., 2019).

Further change stems from the increasing formation of PSS (Rexfelt et al., 2011), as Schweitzer et al. (2019) have stated, the majority of literature still only takes a perspective on products or services. Many studies focus merely on service development (Edvardsson et al., 2012; Hughes \& Brooks, 2019; Jouny-Rivier et al., 2017; Moeller, 2008). Due to these emerging PSS, new methods such as Design Thinking are increasingly integrated, because this is a systematic customer-centric problem-solving process (Scherer et al., 2016). Design Thinking facilitates the shift from technology-driven development towards a thorough understanding of user needs and translating them into products and services. Designers have to intensify CI and go beyond pure customer orientation towards co-creation, which is defined as "the active involvement of customers in firms' development activities" (Balau et al., 2020). Since this is achieved by direct $\mathrm{CI}$ in all phases of development using various methods, this gives the topic of CI a new wave of attention (Fuchs \& Golenhofen, 2019).

Since innumerable methods of CI exist, it is not astonishing that much literature covers these various methods (Pelka, 2018; Schweitzer et al., 2019; Witell et al., 2011; Wuttke et al., 2019; Zogaj \& Bretschneider, 2012). It was already evident before Design Thinking that in order to cope with increasing complexity, frameworks were required to select and combine different methods (Edvardsson et al., 2012; Fueller et al., 2014; Piller \& Vossen, 2010; Rexfelt et al., 2011). Constantly progressing technologies enable even faster and simpler CI, meaning that this area will expand further (Ernst et al., 2017; Zogaj \& Bretschneider, 2012).

Despite intensive research, implementation in practice remains a challenge due to CI's enormous complexity (Zogaj \& Bretschneider, 2012), especially in the B2B sector (Wiedmann $\&$ Pankalla, 2011). To address this and achieve industrial applicability, reusable and structured process models are required (Rexfelt et al., 2011; Wuttke et al., 2019). The existing initial approaches are mostly limited, such as the models of Enkel et al. (2005) and Wecht (2006), both discuss the innovation process. Aquilani et al. (2016) have developed a very specific model, though they have made a significant contribution by conceptualizing it as a never-ending cycle, which facilitates the reuse. Rexfelt et al. (2011) and Pelka (2018) provided holistic process models for the automotive industry that give guidance for the combination of different methods. Wuttke et al. (2019) support this and discuss the individuality of the CI process while underlining the lack of a holistic approach that combines different methods in the various phases. Balau et al. (2020) have recently reiterated the need to deepen the process of CI and ensure that knowledge is transferred efficiently into the organization.

The recent emergence of CI procedural models indicates the need for decision support to ensure effective and sustainable implementation in practice. This is vital given the complexity of CI, as different requirements coincide, such as varying goals, different methodological possibilities, diverse requirements by the respective phases and also divisions and generally heterogeneous customers. All in all, there is a research gap because it is not clearly understood why CI is still so problematic in practice and which factors affect the industrial application and how a future CI process would have to be designed. A holistic, reusable CI model that efficiently transfers customer know-how into the organization in a persistent form is missing. 


\subsection{Empirical evidence from the industrial perspective}

The qualitative expert interviews are rich in information and are an essential part of this research project, especially regarding the problem understanding and thus vital for this research clarification as well as of the following Descriptive Study I within the DRM. Q2 is only briefly outlined here, as it was primarily included to ensure that respondents have a similar understanding of CI and whether this agrees with the literature.

The core objectives have hardly changed over time and were already present in older literature and have been confirmed by the experts. All OEM experts mentioned the need for customization in the first sentences of their answer to Q2. Namely, that "no matter what industry, as an OEM you have to become a solution provider and this is only possible if you understand the needs of the customer, in order not to miss the market and therefore, CI is crucial". Additionally, increased customer requirements, value creation, innovation urge, market success and competitive intensity were also identified as primary objectives. New and less well understood in the literature are goals that are related to the research gap discussed here. These include the paradigm shift away from technology push. OEMs are currently too convinced of their competences and that they can develop products exclusively with internal resources. This is especially difficult in the B2B sector in connection with investment goods. Product managers and developers do not use the products themselves, as it would be the case, for example, with consumer goods in the $\mathrm{B} 2 \mathrm{C}$ sector. This leads to a lack of usage-related knowledge, which is the most frequently indicated goal among customers. Besides, there is the difficulty due to the long product life cycle of these highly specific investment goods. The implementation of customer requirements takes time and complicates CI. However, CI can also improve the B2B sector by further strengthening the already intensive partnership. This is because customers are motivated to get involved, as the products are tools for them. The goal of increasing knowledge credibility by direct contact to customers was also frequently expressed. The marketing effect is a positive side effect of CI and should increase sales by applying messages like "developed with customers for customers". Another goal worth mentioning is the market characteristics. In the industry studied, a few large companies face a highly fragmented market with many small customers. This is hardly addressed at present and leads to mostly large customers being involved, which affects the representativity.

After a common understanding of CI was established, the experts were asked about the current situation. The analysis of this should provide certain information about the implementation difficulties in practice. In Figure 1, Q3 and Q5 have been graphically summarized to give a first impression of the as-is situation from the perspective of the OEMs and customers.
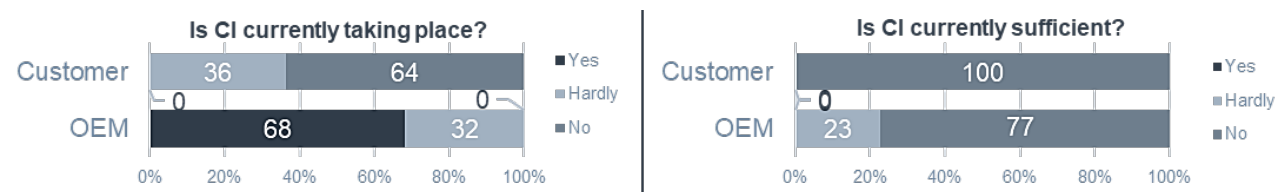

Figure 1. Graphical presentation of questions 3 and 5 from the expert interviews

For the responses, a 3-point Likert scale was used due to its quickness. The loss of information with this small scale is tolerable since these are yes or no questions and the subsequent questions aim to provide detailed information. Based on the expert survey, it can be seen that there is a considerable discrepancy between the perception of the OEM and that of the customer. None of the customers says that CI is currently taking place, only 36 percent said hardly any and referred in this context to sales activities, and the majority of 64 percent said clearly no. There is a more favorable opinion from the OEM experts. Nobody claims that $\mathrm{CI}$ is not taking place, and the majority of 68 percent said straight yes. However, there was a consensus between the two parties as to whether the as-is situation was satisfactory for them. In fact, no one of them 
said that the present situation regarding CI was acceptable. On the OEM side, only 23 percent replied partially and 77 percent no. On the customer side, the result was even more explicit, 100 percent said no to this question and that CI must improve. Since all experts are dissatisfied with the as-is situation, a closer look will be taken in the following.

\subsubsection{Qualitative review of the as-is situation in industrial practice}

For a systematic analysis as well as for a holistic solution approach, problem dimensions are introduced which are strongly oriented towards those of Herfeld (2007). Namely 'human', 'method \& tools', 'data \& knowledge management' and 'process'. Concerning the human factor, it was found that the willingness and trust of customers are already present to a large extent. Expectation management was described by both parties as positive and also that customers have the appropriate know-how and ability to articulate their needs. Some OEM experts said that due to a missing process it is often costly and time-consuming to carry out CI and therefore this is partially perceived as an annoying To Do, and they are less motivated.

Regarding method \& tools, it was found that the respondents have little knowledge about the range of integration possibilities and also when which method should be used. Often only interviews or online surveys were stated here, such as a satisfaction survey on sales. Another example from a customer was a test vehicle in real operation. This was provided free of charge by the OEM for data collection purposes. The customer was not further involved and received no information about the results or anything else. Among the surveyed experts were few positive outliers from the research and digital departments. In the research division, users are regularly involved for analysis and thus the division have profound knowledge of selected methods. The digital expert reported on new Design Thinking methods that focus on usercentered development. This has already been successfully implemented for software development, but no progress has yet been made in hardware development. Another positive example worth mentioning is a regular expert advisory board with firmly selected customers, which was positively evaluated by both sides.

Concerning data \& knowledge management, it was recognized that due to the organizational structures, the direct customer contact is mostly managed by sales and therefore engineering and product management, have no direct interactions. Based on this set-up, these central divisions receive customer knowledge only indirectly. The consequences mentioned are loss of information and lack of credibility of the forwarded customer opinions. Especially customers fear that usage-related knowledge does not reach the central divisions. CI results are not disseminated centrally and efficiently throughout the entire organization. Even the experts who reported on successful examples of process approaches to CI criticized the further processing of the knowledge gained as problematic and insufficient.

With regard to the process dimension, the fragmented approach is particularly noteworthy; CI methods were isolated, unsystematically applied and mostly controlled by individual persons or divisions. The interviewees often reported in detail about CI application, but these were isolated cases. Only three OEM experts, such as body builders or tractor OEMs, reported on initial process models. Nevertheless, even with these positive outliers, the process is not very systematic, not documented and there is no adaptation to the existing processes. Customers also criticized that a recurring process with structure is currently missing. CI attempts in the as-is situation are too complex as there is no systematic process that combines the various requirements in a modular and flexible approach. OEM employees also question the top management commitment, since $\mathrm{CI}$ is not an integral part of existing organizational processes.

\subsubsection{Influencing factors analysis from industrial perspective and contrasting with research}

Part of this research is also to explore the gap between the academic and the practical perspective. Therefore, an analysis of the IF had to be carried out to determine the cause of the 
implementation problem. For this purpose, in Q6 the experts were asked to indicate all conceivable and valuable IF, regardless of whether they are customer- or organization-related. A very rich set of qualitative data has been collected. The IF were then further analyzed in focus groups with scientists and the research partner. Similar key issues were grouped into categories. These IF categories were then ranked according to the frequency with which the experts mentioned the key issues. A deductive approach was chosen to assign the previously presented problem dimensions to the identified IF. The final data analysis step was a comparison with some existing literature to ascertain, which IF are already known (cf. Table 2).

Table 2. Influencing factors identified from the industrial perspective and compared to literature ${ }^{1}$

\begin{tabular}{|c|c|c|c|}
\hline Influencing Factors (with & frequency ranking) & Key Issues & Literature \\
\hline Representativity & 3 & $\begin{array}{l}\text { Customer fit to respective } \mathrm{Cl} \text { goal, market representatives, generalizable, } \\
\text { no. of customers, qualified ones \& awareness of bias }\end{array}$ & $4,8,12,21$ \\
\hline Process \& control competence & 16 & $\begin{array}{l}\text { Reusable, correct, complete, consistent, clear to prevent fragmented } \\
\text { usage \& disruption in development time, coordination ability }\end{array}$ & $\begin{array}{l}1,2,4,7,8,10,12,19,24, \\
26\end{array}$ \\
\hline $\mathrm{Cl}$ competence & 4 & $\begin{array}{l}\text { Method knowledge, capability to integrate customers \& capability to } \\
\text { combine internal with external resources }\end{array}$ & $8,12,19,27$ \\
\hline Multidisciplinarity & 17 & $\begin{array}{l}\text { Harmonization of departmental requirements, collaboration, highness over } \\
\text { the customer degree of decentralization \& political affairs }\end{array}$ & $7,13,19$ \\
\hline Communication competence & 13 & $\begin{array}{l}\text { Ability to obtain information, knowledge transfer, level of information flow \& } \\
\text { credibility of communicated results }\end{array}$ & $\begin{array}{l}1,2,4,10,13,17,20 \\
24,27,28\end{array}$ \\
\hline Knowledge representation & 2 & $\begin{array}{l}\text { Efficient diffusion, abstraction level, updatable, receiver suitability, person } \\
\text { \& translation independent, link to product attributes \& identify next } \mathrm{Cl}\end{array}$ & 7,13 \\
\hline Top-management & 13 & $\begin{array}{l}\text { Top-management commitment, incentives, reporting mechanism, } \\
\text { socializing managers \& changing managerial practices }\end{array}$ & $1,8,17,18$ \\
\hline Usability & 10 & $\begin{array}{l}\text { Process complexity, simplicity, compatibility with existing processes and } \\
\text { structures \& effectiveness and efficiency }\end{array}$ & $\begin{array}{l}7,12,13,14,19,22,26 \\
27\end{array}$ \\
\hline Possibility of modularization & 2 & $\begin{array}{l}\text { Flexible structures, which can be quickly adapted to PEP, modular } \\
\text { construction system and other processes }\end{array}$ & $7,13,16$ \\
\hline Utilization of IT & 11 & $\begin{array}{l}\text { Generating data, distribution of data, accessibility to data, data analysis \& } \\
\text { data storage }\end{array}$ & 13,20 \\
\hline Resources & & $\begin{array}{l}\text { Financial, capacity employee, technical \& social skills employee, } \\
\text { infrastructure, technology, facilities \& realization capacity }\end{array}$ & $\begin{array}{l}4,8,9,10,11,12,14 \\
15,18,20,22,23,24\end{array}$ \\
\hline Specialist competence & 3 & $\begin{array}{l}\text { Appropriate \& relevant knowledge, farsightedness, creativity, problem- } \\
\text { solving skills, ability to articulate needs \& innovation capability }\end{array}$ & $3,4,6,19,25,27,28$ \\
\hline Expectation management & 4 & $\begin{array}{l}\text { Open communication, significance of opinion, understandable for } \\
\text { customers, perceived value in terms of benefit, fair pricing, cost savings }\end{array}$ & $11,12,14,15,19,22,25$ \\
\hline $\begin{array}{c}\text { Organizational \& Employee } \\
\text { attitude }\end{array}$ & 9 & $\begin{array}{l}\text { Degree of customer orientation, company's willingness to afford time \& } \\
\text { money, transparency, open mindset \& reflectiveness }\end{array}$ & $\begin{array}{l}2,4,7,9,11,15,17,19 \\
20,21,25\end{array}$ \\
\hline Customers' willingness & & $\begin{array}{l}\text { Transparency, mindset, commitment, time, motivation (extrinsic vs. } \\
\text { Intrinsic), satisfaction level \& opportunistic behavior }\end{array}$ & $\begin{array}{l}1,6,9,14,19,20,21 \\
22,25,27\end{array}$ \\
\hline Type of $\mathrm{Cl}$ method & 9 & $\begin{array}{l}\text { Degree of interactivity, technique, duration, role of the customer, direct vs. } \\
\text { indirect \& online vs. offline }\end{array}$ & $\begin{array}{l}2,5,8,11,13,17,19 \\
21,22,23,25,26,27,28\end{array}$ \\
\hline Stage in development process & 5 & $\begin{array}{l}\text { Stage of development process is crucial, varying requirements and } \\
\text { intensity of } \mathrm{Cl} \text {, require different methods }\end{array}$ & $\begin{array}{l}7,8,13,14,15,16,17 \\
19,21,25,26,27\end{array}$ \\
\hline Trust & $4 \quad 2$ & $\begin{array}{l}\text { Partnership, sensitivity, industry-specific mentality, access and information } \\
\text { symmetry \& ownership of intellectual property }\end{array}$ & $4,11,14,18,22,25,27$ \\
\hline Clear objectives & 32 & $\begin{array}{l}\text { Expected contribution, type of information, product or service \& radical vs. } \\
\text { incremental }\end{array}$ & $\begin{array}{l}2,5,7,11,19,21,25 \\
26,27,28\end{array}$ \\
\hline Experience & 1 & Atmosphere, treatment by organization / employee, degree of autonomy & $4,9,11,17,18,19,27$ \\
\hline
\end{tabular}

It was found that all IF collected in practice are at least known in the literature and no completely new factors were identified. This suggests that either the IF are not yet fully understood in literature or that a consideration of several in combination is required to increase the applicability of CI. A distinct pattern can be observed. The experts have emphasized the dimensions process and data $\&$ knowledge management more than methods $\&$ tools and the human factor. This insight is a fundamental part of the research gap and has a high impact on the desired future situation for CI, which is why it is discussed in more detail in the next section. To further examine these IFs and their respective extent, more quantitative research is needed.

${ }^{1}$ Aquilani et al., 2016; ${ }^{2}$ Balau et al., 2020; ${ }^{3}$ Edvardsson et al., 2012; ${ }^{4}$ Ehlen, 2015; ${ }^{5}$ Enkel et al., $2005 ;{ }^{6}$ Ernst et al., 2017; ${ }^{7}$ Fuchs \& Golenhofen, 2019; ${ }^{8}$ Fueller et al., 2014; ${ }^{9}$ Hughes \& Brooks, 2019; ${ }^{10}$ Jacob, 2006; ${ }^{11}$ JounyRivier et al., 2017; ${ }^{12}$ Kuhl \& Krause, 2019; ${ }^{13}$ Legardeur et al., 2010; ${ }^{14}$ Lorenzo-Romero et al., 2014; ${ }^{15}$ Moeller, 2008; ${ }^{16}$ Pelka, 2018; ${ }^{17}$ Piller \& Vossen, 2010; ${ }^{18}$ Prahalad \& Ramaswamy, 2004; ${ }^{19}$ Rexfelt et al., 2011; ${ }^{20}$ Scherer et al., 2016; ${ }^{21}$ Schweitzer et al., 2019; ${ }^{22}$ Song et al., 2013; ${ }^{23}$ Wecht, 2006; ${ }^{24}$ Wiedmann \& Pankalla, 2011; ${ }^{25}$ Witell et al., 2011; ${ }^{26}$ Wuttke et al., 2019; ${ }^{27}$ Zhang et al., 2015; ${ }^{28}$ Zogaj \& Bretschneider, 2012 


\section{Discussion and managerial implications}

As this paper is geared towards the first DRM stage, the aim is to generate an initial understanding of the problem and to formulate objectives. Comparisons between industrial practice and research were made to identify the IF that prevent a successful implementation from theory to practice. It was found that the scope of the preliminary IF is greater than expected, and there is considerable literature on this topic. Two significant findings were discovered here, which concern the problem dimensions identified as most important. These are probably not fully understood in research as they were mainly considered in isolation.

The first finding is that the analysis of the IF reveals that especially those aspects that relate to the organizational level, such as multidisciplinary, are not addressed and considered in combination, which leads to the absence of a comprehensive CI process. An exemplary missing property for such a process is that it is consistent and circular due to continuous improvement and NPD. This leads to the second insight in the data and knowledge management dimension. The know-how generated using CI must be representative and efficiently represented in order to ensure its persistence within the organization. Especially with long development cycles, knowledge does not have to be constantly renewed, but can be maintained and reused. Furthermore, an efficient translation and dissemination of CI results within the organization are essential, since this subject is at the interface of various disciplines, such as sales, product management and engineering. As today, in times of continually improving technologies, vast amounts of data are expected, it is crucial to do this efficiently to avoid falling into a complexity trap between CI effort and expected benefit. These are important contributions from this project, which clarify which IF need to be investigated in more detail, because they complicate the applicability in practice, even though there is a lot of research on CI in general.

A final component of the DRM research clarification is a preliminary reference model. For this purpose, a sketch of the desired to-be situation with regard to each phase of the engineering design process was first created, using the expert answers to Q7 (cf. Figure 2).

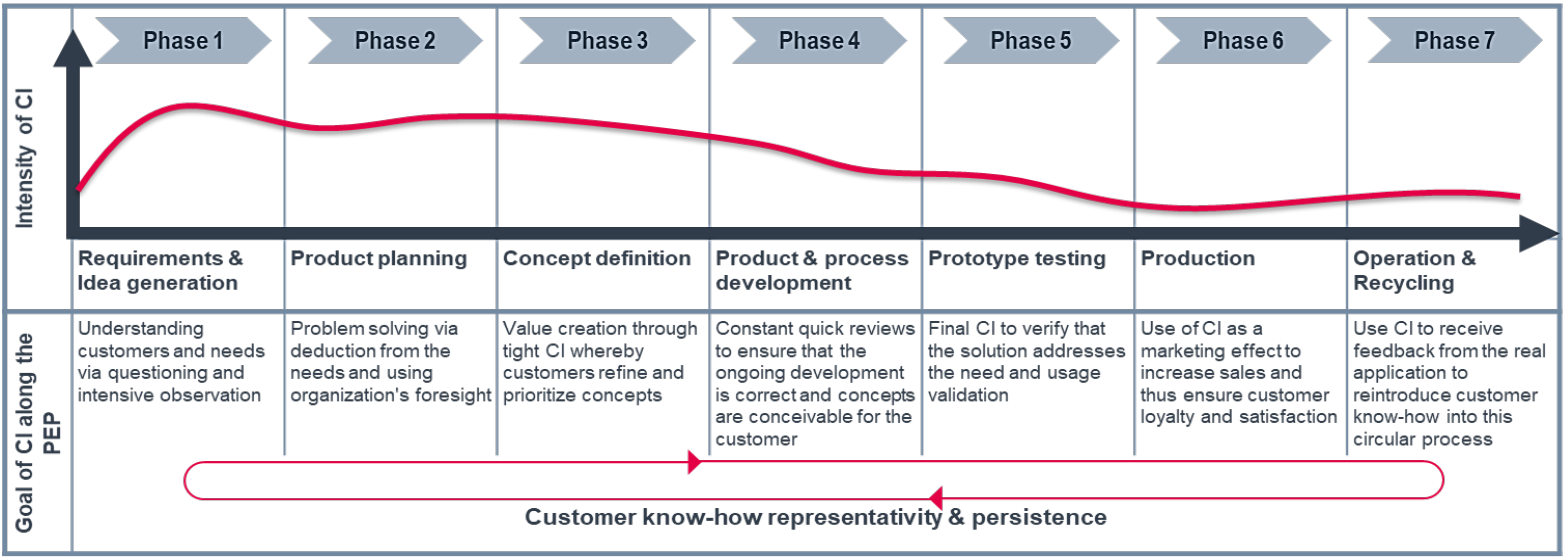

Figure 2. Qualitative illustration of the to-be situation for CI along the development process

All experts emphasized the importance of a continuous CI along the development process. The plotted curve is exemplary and is based on the qualitative assessment by the experts to illustrate the varying intensity of $\mathrm{CI}$ along the individual phases. The underlying objectives also differ, so that a variety of CI methods are required, which in turn underlines the importance of a modular process. Fuchs \& Golenhofen (2019) have reached comparable conclusions concerning Design Thinking. The customer is more involved, especially at the beginning, and thereafter more agile and iterative. The aim is to understand and solve the customer's problems, whereby the solution approach remains unclear at first and is explored together.

This leads to a preliminary reference model for CI to enable organizations to apply CI in challenging circumstances (cf. Figure 3). This comprehensive procedural approach enables 
systematic CI, whereby especially the previously discussed weaknesses of the as-is situation are addressed. The model will be refined in the course of research to achieve the to-be situation.

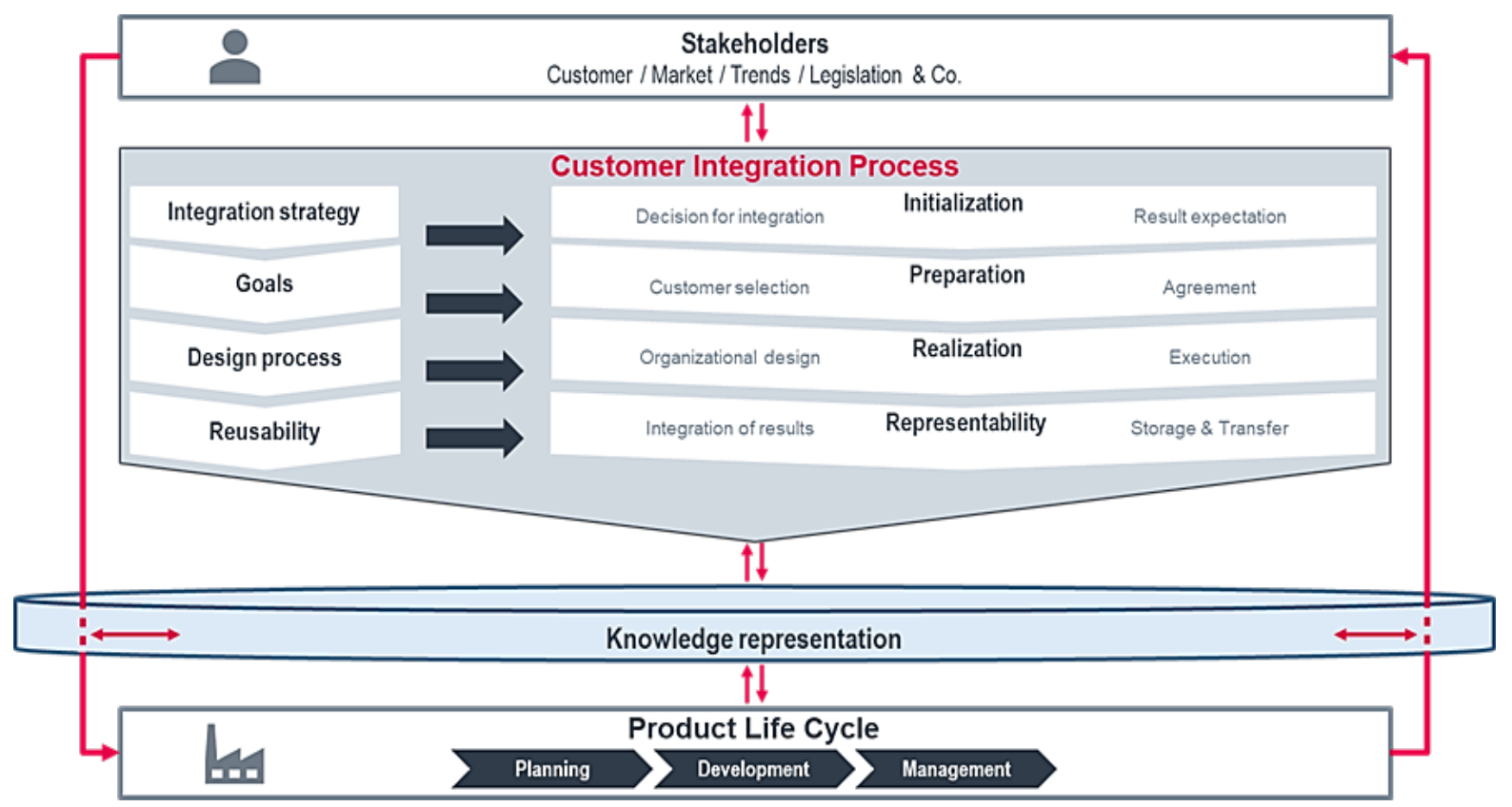

Figure 3. Initial idea for a solution approach in form of a comprehensive procedural model

Within this model, existing models from the literature on individual aspects of CI, such as method selection or customer choice, are included. Pelka's (2018) approach will be partially adopted and, with regard to academia and practice it will be investigated in more detail what is already available, which existing models can be used as a reference and what aspects need to be added to address the problems identified here. A common denominator must anchor the CI model in the existing organizational processes. This leads to these overarching research question of how a customer integration model can be designed to transfer customer knowledge across divisions and along the entire product life cycle into a knowledge representation in the organization and ensure its persistence? In summary, the following requirements for a CI model can be formulated, which were confirmed by the analysis of the IF found in research and practice and are in accordance with Becker et al. (1995). A consistent and clear process is required that is not too complex, but rather concise so that it is applicable while being comprehensive and complete in terms of incorporating all relevant IF.

\section{Conclusion}

This paper focuses on the challenge of CI and its industrial applicability in the case of CV development. After an introduction and the description of the methodological approach, the findings from a literature analysis and an industrial perspective are presented and the as-is situation is discussed. The first research question was answered, and despite plenty of literature in this field, it was found that the as-is situation is not satisfactory. The literature review revealed the absence of a comprehensive meta-model, which exceeds the early phase and provides methods on how to reach reusable and persistent customer know-how by using CI. This corresponds with the practice view. A gap between the as-is situation and the to-be situation with regards to CI was found. Based on this, decisive IF were identified from the practical perspective and compared with existing literature. The highest relevance was attributed to the problem dimensions process and data \& knowledge management. Lastly, a first solution approach is outlined, a process model for CI with the focus on ensuring knowledge representation and persistence within the organization. The credibility of the newly proposed 
framework will lie in the extension of theoretical concepts and addressing the newly identified practical problem dimensions. The objective of the CI process model, which is the core of future research of this project, is to support OEMs in developing customer solutions in the B2B sector, who are confronted with heterogeneous customer needs leading to a variant-rich product portfolio. Future research will examine the most important IF and their impact as well as the detailed elaboration of the meta-model and the individual processes of it.

\section{References}

Aquilani, B., Silvestri, C., \& Ruggieri, A. (2016). Sustainability, TQM and value co-creation processes: The role of critical success factors. Sustainability, 8(10), 995.

Balau, G., van der Bij, H., \& Faems, D. (2020). Should SMEs get out of the building? Examining the role of customer co-creation on radical organizational creativity. R\&D Management.

Becker, J., Rosemann, M., \& Schütte, R. (1995). Grundsätze ordnungsmäßiger modellierung. Wirtschaftsinformatik, 37(5), 435-445.

Blessing, L. T., \& Chakrabarti, A. (2009). DRM: A design reseach methodology (pp. 13-42). Springer London.

Bryman, A. \& Bell, E. (2011). "Business Research Methods" $3^{\text {rd }}$ ed. Oxford University Press.

Edvardsson, B., Kristensson, P., Magnusson, P., \& Sundström, E. (2012). Customer integration within service development $-\mathrm{A}$ review of methods and an analysis of insitu and exsitu contributions. Technovation, 32(7-8), 419-429.

Ehlen, C. G. J. M. (2015). Co-creation of innovation: Investment with and in social capital. Studies on Collaborafion between Educafion-Industry-Government.

Enkel, E., Perez-Freije, J., \& Gassmann, O. (2005). Minimizing market risks through customer integration in new product development: learning from bad practice. Creativity and Innovation Management, 14(4), 425-437.

Ernst, H., Hoyer, W., Krafft, M., \& Soll, J. H. (2017). Virtual Co-Creation with Customers in the Early Stages of New Product Development. Available at SSRN 3053800.

Fuchs, C., \& Golenhofen, F. J. (2019). Creating customer value through design thinking. In Mastering Disruption and Innovation in Product Management (pp. 77-102). Springer, Cham.

Fueller, K., Engel, T., Benz, M., Goswami, S., \& Krcmar, H. (2014). A matrix for selecting appropriate customer integration methods. In POMS International Conference, Singapore.

Herfeld, U. (2007). Matrix-basierte Verknüpfung von Komponenten und Funktionen zur Integration von Konstruktion und numerischer Simulation (Doctoral dissertation, Technische Universität München).

Hughes, T., \& Brooks, I. (2019). Co-creation of value: A customer-integration approach. In B. Nguyen, T. Melewar, \& J. Hemsley-Brown (Eds.), Strategic Brand Management in Higher EducationRoutledge.

Jacob, F. (2006). Preparing industrial suppliers for customer integration. Industrial Marketing Management, 35(1), 45-56.

Jouny-Rivier, E., Reynoso, J., \& Edvardsson, B. (2017). Determinants of services co-creation with business customers. Journal of Services Marketing.

Kreimeyer, M., Förg, A. \& Lienkamp, M. (2013). Multi-level modular kit development for commercial vehicles. In VDI Factagung NFZ 2013 (pp.99-112). Celle:VDI-Verlag.

Kuhl, J., \& Krause, D. (2019). Strategies for Customer Satisfaction and Customer Requirement Fulfillment within the Trend of Individualization. Procedia CIRP, 84, 130-135.

Legardeur, J., Boujut, J. F., \& Tiger, H. (2010). Lessons learned from an empirical study of 
the early design phases of an unfulfilled innovation. Research in Engineering Design, 21(4), 249-262.

Lewin, K. (1951). Field theory in social science.

Lindemann, U., \& Baumberger, G. C. (2006). Individualisierte Produkte. In Individualisierte Produkte-Komplexität beherrschen in Entwicklung und Produktion (pp. 7-16). Springer, Berlin, Heidelberg.

Lorenzo-Romero, C., Constantinides, E., \& Brünink, L. A. (2014). Co-creation: Customer integration in social media based product and service development. Procedia-Social and Behavioral Sciences, 148, 383-396.

Moeller, S. (2008). Customer integration - a key to an implementation perspective of service provision. Journal of service research, 11(2), 197-210.

Pelka, A. (2018). Die Ermittlung von Kundenanforderungen und ihre Transformation in technologische Produktinnovationen in der frühen Phase der automobilen Produktentstehung (Vol. 112). Springer-Verlag.

Piller, F. T., Ihl, C., \& Vossen, A. (2010). A typology of customer co-creation in the innovation process. Available at SSRN 1732127.

Prahalad, C. K., \& Ramaswamy, V. (2004). Co-creation experiences: The next practice in value creation. Journal of interactive marketing, 18(3), 5-14.

Rexfelt, O., Almefelt, L., Zackrisson, D., Hallman, T., Malmqvist, J., \& Karlsson, M. (2011). A proposal for a structured approach for cross-company teamwork: a case study of involving the customer in service innovation. Research in engineering design, 22(3), 153-171.

Scherer, J. O., Kloeckner, A. P., Ribeiro, J. L. D., Pezzotta, G., \& Pirola, F. (2016). Productservice system (PSS) design: using design thinking and business analytics to improve PSS design. In 8th CIRP IPSS Conference. Product-Service Systems across Life Cycle (Vol. 47, pp. 341-346). Elsevier.

Schweitzer, F., Van den Hende, E. A., \& Hultink, E. J. (2019). There's more than one perspective to take into account for successful customer integration into radical new product innovation: A framework and research agenda. IEEE Transactions on Engineering Management.

Song, W., Ming, X., \& Xu, Z. (2013). Risk evaluation of customer integration in new product development under uncertainty. Computers \& Industrial Engineering, 65(3), 402-412.

Wecht, C. (2006). Active customer roles during the innovation front-end: theoretical foundations and managerial implications.

Wiedmann, K. P., \& Pankalla, L. (2011). Anforderungen an die Kundenintegrationskompetenz als Grundlage einer Erfolg versprechenden Kundenintegration in Innovationsprozesse-Erste Skizzen zu einem theoretischen Bezugsrahmen. In Integrierte Unternehmungsführung (pp. 67-81). Gabler.

Witell, L., Kristensson, P., Gustafsson, A., \& Löfgren, M. (2011). Idea generation: customer co-creation versus traditional market research techniques. Journal of Service Management.

Wuttke, C. C., Deck, B., Haussmann, Y., Hülsen, W. V., Ilg, J., Schneider, S., ... \& Pester, M. (2019). Individualized Customer Integration Process for the Design of IPSS. Procedia CIRP, 83, 83-88.

Zhang, X., Yang, Y., \& Su, J. (2015). Risk identification and evaluation of customer collaboration in product development. Journal of Industrial Engineering and Management, 8(3), 928-942.

Zogaj, S., \& Bretschneider, U. (2012). Customer integration in new product development: a literature review concerning the appropriateness of different customer integration methods to attain customer knowledge. Available at SSRN 2485240. 